\title{
XXII. On isomerism
}

\section{M.M. Pattison Muir F.R.S.E.}

To cite this article: M.M. Pattison Muir F.R.S.E. (1876) XXII. On isomerism, Philosophical Magazine Series 5, 2:10, 161-172, DOI: 10.1080/14786447608639087

To link to this article: http://dx.doi.org/10.1080/14786447608639087

$$
\text { 曲 Published online: } 13 \text { May } 2009 .
$$

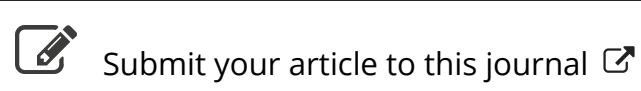

\footnotetext{
Џll Article views: 3
}

Q View related articles $\sqsubset$ 
LONDON, EDINBURGH, AND DUBLIN

\title{
PHILOSOPHICAL MAGAZINE
}

\author{
AND \\ JOURNAL OF SCIENCE.
}

[FIFTH SERIES.]

$S E P T E M B E R$.

XXII. On Isomerism. By M. M. PatTison MuIR, F.R.S.E., Assistant-Lecturer on Chemistry, the Owens College, Manchester*.

1. TN a paper published in this Magazine ([V.] vol. ii. p. 1) I upheld the proposition that our ordinary chemical notation indirectly expresses changes in the form of the energy of a system of bodies reacting chemically upon one another. Among the phenomena which are undoubtedly connected with such changes of energy isomerism holds an important position. I endeavoured to show that the facts of isomerism, while pointing to differences in the energies of the isomeric bodies, were not inconsistent with the generally accepted theory, according to which isomeric molecules are possessed of different atomic structures.

I shall now endeavour to supplement the remarks made in the paper referred to by others having a similar bearing.

2. The "position theory" of isomerism would seem to account for the phenomena by assigning to the atoms which form two isomeric molecules different positions in the two molecules; the "energy theory" of isomerism would trace the cause of the phenomena to those "conditions of action under which forces effect a fixed alteration in one or more functions of radicles."

But these theories are not, it seems to me, incompatible. Changes of function are associated with changes of energy, and these again with changes in the "configuration of a material system."

* Communicated by the Anthor.

Phil. Mag. S. 5. Vol. 2. No. 10. Sept. 1876. 
Granted that there is an inner structure of the molecule, we should, à priori, expect that changes in this structure would be correlated with changes in the functions of the molecule. And we must imagine that atomic motions are continually taking place in the molecule; hence under certain conditions these motions may be directed so as to result in the development of a form of energy different from that which is developed when the atomic motions are otherwise directed. If it be urged that the terms "molecule," "atomic motion," \&c. involve theoretical considerations, we grant the objection, if objection it be. The same objection would apply to very many of the most important dicta of science. Still it might be said that by limiting our attention to the changes of function (or of energy) we are dealing with facts, and with facts alone.

But if we speak of energy at all we must, I think, imagine a something which is "the seat or vehicle of energy;" to this something we give the name of matter. Hence a change of energy appears to involve in some way a change of matter. If the body, the energy of which changes form, is not possessed of a molecular and atomic structure, but is continuous, it must at any rate have a grained structure of some kind (otherwise many well-established phenomena remain utterly unaccounted for); and we can then imagine some kind of change in the position of these grains. Such a theory of infinite divisibility of matter does not, however, explain so many facts as the other (i.e. the molecular theory) does. We therefore prefer the molecular theory, and seek to associate with changes in the energy of chemical substances changes also in the structure of the matter composing these substances.

3 . Of course it is very possible to put a wrong meaning upon the structural formulæ which are used to express the facts of isomerism. Three alcohols having the empirical formula $\mathrm{C}_{4} \mathrm{H}_{10} \mathrm{O}$ are known. These bodies do not undergo the same reactions with the same reagents. In the formation of these bodies "a fixed alteration has been produced in one or more of their functions." Would it then be enough to inquire "under what conditions of action" these alterations are produced? Surely not; we seek to determine whether there are differences in the inner mechanism of those small parts of the substances which remain united when the substances are hot. And when we have, as it would appear, learned that there are such differences, we of course seek to express these differences in the formulæ given to the substances. Thus to socalled normal butylic alcohol is generally assigned the structural formula $\mathrm{CH}_{2}\left(\mathrm{C}_{3} \mathrm{H}_{7}\right) \mathrm{OH}$; to secondary butylic alcohol 
the formula $\mathrm{CH}\left(\mathrm{CH}_{3}\right)\left(\mathrm{C}_{2} \mathrm{H}_{5}\right) \mathrm{OH}$; and to tertiary butylic alcohol the formula $\mathrm{C}\left(\mathrm{CH}_{3}\right)_{3} \mathrm{OH}$. Graphically written these formulæ become<smiles>CCC(C)C(C)O</smiles><smiles>CC(O)C(C)(C)C</smiles>

In many text-books these differences are expressed by some such statement as :- " in the primary alcohol the $\mathrm{OH}$ group is attached to a carbon atom which is itself attached to one other; in the secondary alcohol the $\mathrm{OH}$ group is attached to a carbon atom which is itself attached to two others; and in the tertiary alcohol the $\mathrm{OH}$ group is attached to a carbon atom which is itself attached to three other carbon atoms." Such expressions as "attached to a carbon atom at the beginning of the chain," "attached to a carbon atom in the middle of the chain," \&c., are also used when speaking of isomerism. From these and similar expressions one might conclude, as some of the opponents of the position theory would almost appear to do, that the molecule is regarded as a fixed structure, the different parts of which are rigidly arranged around a centre (just as one might stick balls of clay on to stone), and that by removing one of the pieces which compose this molecule and placing it in another fixed position an isomeric molecule is produced.

Language which would give any countenance to such crude ideas as this should certainly not be made use of. The upholders of the position theory have given grounds for faultfinding. But is the whole theory to be rejected because of crudities in the manner of stating it?

That the structural and graphic formule quoted above do give to the chemist a very large amount of information concerning the three butylie alcohols is patent to all; and that the main idea implied in them, viz that the atoms composing the molecules, although the same in kind and in number in 
each of the three, are nevertheless not arranged in the same manner in each, is, I think, not opposed to but is in keeping with known facts.

4. Granting, then, that change in the form of energy and change of molecular structure are correlated in isomeric bodies, the inquiry into the facts of isomerism would naturally branch out into two directions.

Chemists would seek to determine what are the atomic arrangements in isomeric molecules, and what are the differences in the energies of these molecules.

The first part of this inquiry has been approached by a method which seems to present the most probable chances of success, viz. by studying the reactions of formation and of decomposition of isomers. These reactions have been in many instances generalized, and the results have been embodied in appropriate formulæ. From the generalizations so reached some slight idea of the atomic arrangement (granting, of course, that such arrangement has an actual existence) of many isomeric bodies has been attained to.

But even in this part of the inquiry we have still very much to learn. Attention has not, it appears to me, been sufficiently paid to the fact that atomic structure involves atomic motion of some kind.

In the second part of the inquiry (that, namely, which relates to changes of energy) little or no progress has been made. The subject is beset with many difficulties; but in this field many of the future triumphs of chemical science will doubtless be achieved.

5. As a preliminary investigation it would be well that the data concerning the physical properties of isomers should be more carefully observed. Something has, it is true, been done in this direction. Thus we know that the boiling-points of isomeric compounds, which have, so far as we can judge from their reactions, a similar molecular structure, are nearly identical; whereas when the molecular structure of isomeric compounds is essentially different we find a marked difference between the boiling-points of these compounds. We are indeed in some cases able to trace a somewhat regular alteration in the boiling-points of the members of an isomeric series and to correlate this with a regular alteration in molecular structure; thus the boiling-points of the four butylic alcohols differ by about $11^{\circ}$. By comparing the structural formulæ of these compounds (i. e. formulæ which generalize the reactions of formation and of decomposition which these bodies exhibit) a gradual closing-up, so to speak, of the molecular structure becomes apparent. 


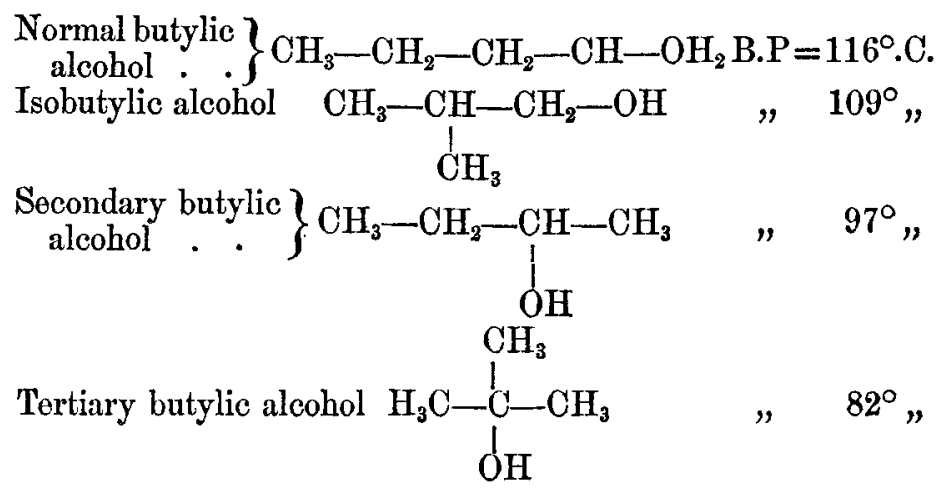

So, again, we learn from experiment that a substance whose reactions are best expressed by writing its formula as containing the group $\mathrm{OH}$, is generally possessed of a higher boilingpoint than another isomeric substance which does not appear to contain this group; hence from a consideration of the boiling-points of ethylic alcohol, and of methylic ether respectively $\left(78^{\circ}\right.$ and $-21^{\circ} \mathrm{C}$.), and from a knowledge of the two possible modifications of the empirical formula $\left(\mathrm{C}_{2} \mathrm{H}_{6} \mathrm{O}\right)$, which is common to each, we should expect, without a previous study of the reactions of these bodies, that the structural formula of the alcohol would be $\mathrm{CH}_{3}-\mathrm{CH}_{2}-\mathrm{OH}$, and of the ether $\mathrm{CH}_{3}-\mathrm{O}-\mathrm{CH}_{3}$.

More careful and extended observations of the boiling-points of isomeric compounds will doubtless throw considerable light on their molecular structure. The specific volumes of isomeric bodies are also, it would appear, connected with their molecular structure. Thus according to Kopp the specific volumes of acetic acid and methylic formate are almost identical ; their structural formulæ are likewise analogous, viz. $\mathrm{CH}_{3}-\mathrm{CO}-\mathrm{OH}$ and $\mathrm{H}-\mathrm{CO}-\mathrm{O}-\mathrm{CH}_{3}$ respectively.

The researches of Thorpe, part of which have been already published, will probably help to elucidate the connexion which exists between specific volume and isomerism.

From a study of the heat of combustion and of formation of isomeric substances, we may also hope for knowledge concerning the second part of the general problem of isomerism. May we not suppose that in certain isomers the energy exists in a more available form than it does in others, perhaps even in other members of the same group? We know that under certain conditions energy may be in a more available form than under other conditions; is there such a differenco in the energy of isomers? Supposing that this is the case, availability 
will depend on the position of the parts; hence the two theories will be complementary of each other.

6. One of the difficulties in the way of explaining the facts of isomerism in terms of the molecular theory arises from our ignorance of the conditions which influence the linkingtogether of atoms in a molecule. Given the formula of a substance and the valency of the atoms, it is possible to arrange the symbols in a certain number of ways only; each of these methods of arrangement may represent an isomeric body. Bat we have often very good reasons for believing that of these possible methods of arrangement two or more will represent substances which are actrally identical, not isomeric, with each other.

Thus if we replace one hydrogen atom in marsh-gas by chlorine we might arrange the symbols representing the resultant in four ways :-<smiles>ClCCl</smiles><smiles>ClCCl</smiles><smiles>CCl</smiles><smiles>ClCCl</smiles>

Yet we know that but one substance is invariably produced in the foregoing reaction. Hence we conclade that the four "affinities" or four "equivalents" of carbon are, in this case, of equal value. In other instances, however, it would appear as if the "affinities" of an elementary atom were not all of equal value. Thus we know that phosphorus pentachloride, $\mathrm{PCl}_{5}$, at a moderate temperature splits up into $\mathrm{PCl}_{3}$ and $\mathrm{Cl}_{2} ;$ hence we might suppose that two of the chlorine atoms are held to the phosphorus atom less firmly than the remaining three ${ }^{*}$. Have we here the existence of weaker and stronger affinities in the phosphorus atom? If such differences actually occur, the existence of isomeric bodies may be traced to other causes than that which is generally understood by the phrase "position of the atoms."

7. It would appear very probable that the valency of an atom may be regarded as an expression for the number of directions or of positions in which the atom is capable of exercising chemical force. Thus when we say that the carbon atom is tetravalent we mean, on this hypothesis, that it is capable of exercising chemical force in four directions, or that

* It may be objected that we do not know that $\mathrm{PCI}_{5}$ actually exists. Wurtz's determinations of the vapour-density of this compound (Compt. Rend. vol. Ixxvi. p. 601), carried out in an atmosphere of the trichloride whereby dissociation was prevented, show that $\mathrm{PCI}_{5}$ truly represents the molecular weight of the substance. 
in each of its periodic movements there are four positions in which it can exercise such force. Now if this be granted we are in no way necessitated to suppose that the valency and the total chenical affinity are dependent on one another, nor that the force exercised in one of the four directions or positions is equal in amount to that exercised in each of the other three directions or positions. On this supposition the equivalents or affinities of an atom may differ in value; and the existence of isomers becomes possible, the difference between which is to be traced to the directions in which the chemical force of the constituent atoms of the molecule is exercised.

Such a theory as this has commended itself to several chemists, among others to Crum Brown, who has discussed some of its consequences in a paper published in the 'Journal of the Chemical Society' [2], vol. iii. p. 230.

But, on the other hand, it may be supposed that the equivalents of a given atom have equal values, and, nevertheless, that, owing to the positions of the atoms with respect to each other,"isomeric bodies may arise which shall exhibit differences of behaviour towards the same reagents. Thus, of the isomeric amylic alcohols $\left(\mathrm{C}_{5} \mathrm{H}_{11} \mathrm{OH}\right)$, that whose reactions are best expressed by the constitutional formula

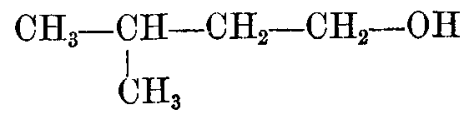

is stable at temperatures at which that having the constitutional formula<smiles>CC(C)C(C)O</smiles>

undergoes dissociation into water and amylene.

The most plausible explanation of this fact appears to be, that, although the affinities of the carbon atoms are all of equal value, yet the group $\mathrm{OH}$ is related in one case to a carbon atom a large number of whose affinities are already "saturated" (to use a common term) with other carbon affinities; whereas in the other case the same group is related to a carbon atom whose affinities are not to so great an extent "saturated" with carbon. Hence, from the different positions occupied by the $\mathrm{OH}$ group, it is possible, during the excursions of the molecule, for those forces which tend to produce molecular disintegration more readily to act upon the $\mathrm{OH}$ group in the one case than in the other.

Again we may suppose that the affinities of any given atom are of equal value, but that as they are successively 
saturated those whieh remain become weaker, if one may use such an expression, and that in some instances the atom does not exercise its total valency because of this weakening of the unsaturated affinities. On this view the whole of the atoms in a molecule must influence the total force exercised by that molecule. Thus the group $\mathrm{OH}$ may, in certain compounds, exchange its hydrogen for metals, while in others, or even in the same compounds, an exchange of hydrogen of this group can only be effected for alcoholic radicles.

The group has thus two functions, an "alcoholic" and an " acid" function. Now we cannot doubt that it is the composition of the remainder of the molecule which chiefly determines the function of the $\mathrm{OH}$ group; the position of the group will of course also exercise an influence. From these considerations it becomes evident that in considering the phenomena exhibited by a chemical molecule we may divide these phenomena into two classes:-first, those which are dependent on the nature of the atoms composing the molecule; and, secondly, those which are dependent on the linking-together or the position of these atoms in the molecule*. The phenomena of isomerism will be influenced by both of these factors; and in endeavouring to explain these phenomena we must overlook neither.

8. We may, then, perhaps imagine the meeting of two molecules, the result of which is to be the formation of new molecules. Molecular dissociation is the first result; for a moment we may picture the atoms vibrating about certain fixed points, at each of which these atoms are capable of exercising their chemical affinity.

Let us suppose that the atoms of molecule $a$ vibrate abont four, and that the atoms of molecule $b$ vibrate about two of these points. Let us further suppose that the force exercised at each of the four points by $a$ atoms is different in amount, but that $b$ atoms exercise the same amount of force at each of their two points.

The atoms become associated and new molecules result, which have a different atomic structure from that of the original molecules $a$ and $b$, and are possessed of an amount of energy differing from that originally possessed by these molecules. But suppose the atoms of molecule $b$ had come within the sphere of action of the atoms of molecule $a$, not at the two positions at which they have, by supposition, actually come within that sphere of action, but at the two remaining positions, we should have a second new set of molecules produced

* See L. Meyer's Moderne Theorien der Chemie, 2nd ed. pp. 138-217; also Crum Brown, loc, eit. 
composed of the same atoms as those which actually were produced, but differing in atomic structure, and in the amount, or at any rate in the form, of the energy possessed by them.

We have here isomerism which is chiefly due to a difference in the value of the equivalents of the atoms of one of the reacting molecules.

Let us now imagine that the atoms of the reacting molecules were capable, as before, of exercising chemical force in four and in two positions respectively, but that the force exercised in each position is the same in amount.

After the atomic interchanges have taken place (we may suppose, for a moment, that these interchanges are accomplished almost instantaneously, and that the resultant molecules are removed from the sphere of mutual action) we have new molecules, still, by supposition, capable of exercising chemical force in two directions; but we may surely suppose that the amount of force to be exercised in each of these directions is not the same now as it was before the atoms had become associated. The occupation, so to speak, of two of the positions of possible action will most probably influence the force which remains to be exercised at the two residual positions, even supposing that originally an equal amount of force was exercised at each of the four. The phenomena of magnetism and of electricity make us acquainted with actions somewhat similar to this.

If we may carry the imagination one step further and suppose that the oceupation of two positions has not only influenced the force to be exercised at the remaining positions, but has also influenced it unequally, we shall now have a molecule which is capable of forming isomers by a process similar to that which was carried out in the case which we first attempted to follow.

If we grant that the occupation of a certain number of the positions at which an atom is capable of exercising chemical force, by another atom, causes a change in the amount of force remaining to be exercised at each of the residual positions, we may also very well grant that upon the nature of the occupying atom will greatly depend the extent of this influence.

By substituting a new occupying atom of equal valency with the original we shall produce not only a new molecule, but a new molecule which is possessed of a different amount of energy from that originally formed. On this supposition we can trace the formation of isomers containing different atomic groups.

Let us suppose that two molecules $a$ and $b$ come within the 
sphere of one another's action; that molecular dissociation occurs, but that in the case of molecule $b$ this is not carried out completely, that instead of the setting-free of single atoms, groups (or at any rate $a$ group) of atoms are produced; these groups become combined with the atoms which formerly constituted molecule $a$ : of the equivalents of these atoms some are satisfied by the new atomic groups; and in this process the remaining equivalents become altered in value (we have supposed that originally the equivalents were all of equal value). Now, on our supposition, the nature of the atomic group or groups which occupy certain of the positions in which the atoms of molecule $a$ are capable of exercising force, will influence the amount of force remaining to be exercised at the unoccupied positions; hence we have only to imagine for the production of an isomer that molecule $a$ comes within the sphere of action of a third molecule $c$ composed of the same atoms as $b$, but capable of splitting up into different atomic groups.

In these supposed formations of isomers we have change of position, change of valency, and change of energy taking place simultaneously.

9. So-called physically isomeric bodies* appear rather to belong to the category of polymeric substances. In most recorded cases it is very probable that the molecular weight of the substance does not remain constant throughout its modifications. If this be so, we should of course have no difficulty in explaining why varying phenomena are presented by each of the modifications.

Laubenheimer (loc. cit.) seeks to explain the formation of so-called physically isomeric bodies by the supposition that the molecules of those modifications which have the higher melting-points are made up, so to speak, of a greater number of fundamental molecules ("Grundmolekule") than the molecules of modifications which melt at lower temperatures. This supposition takes for granted that molecular compounds exist, or at any rate that by the aggregation of molecules (not of atoms) new molecules may be produced,-molecule being taken to mean the smallest portion of a body which holds together when the body is hot.

In a paper published elsewhere $t$ I used the expression "molecular valency" as being perhaps applicable to certain

* Duffy, Chem. Soc. Journ. vol. v. p. 197 ; Zincke, Deut. Chem. Ges. Ber. vol. iv. p. 576; Tollens, ibid. vol. viii. p. 1427; Laubenheimer, ibid. vol. ix. p. 760 , \&c. \&c.

† "On Recent Chemical Researches," Quart. Journ, of Science, January 1876. 
cases of formation of so-called molecular compounds. The use of this term is based on the assumption, which appears to be in keeping with facts, that, although in a given molecule " the lines of force of its atoms are mutually satisfied, there may be directions in which the molecule, as such, may exert a certain amount of chemical energy."

This idea follows naturally from the view of valency and chemical affinity which $I$ have sketched in paragraph 7 of the present paper, because, if the valency of an atom be an expression for the number of directions or positions in which that atom is capable of exercising force, but if the amount of force exercised be independent of the valency, it follows that, althongh an atom exercise its force in each of the possible directions, a part of that force may possibly yet remain unexercised. And may we not imagine that this unexercised force may be exercised by the newly formed molecule, and that in one or more directions?

A view somewhat similar to this was put forward by Mills some years age*. If we grant " molecular valency," we can easily see that the formation of physically isomeric bodies becomes possible according to the supposition that the difference between these bodies is to be traced to the placing together" of a greater or less number of "fundamental molecules" in the molecule of each.

But if compounds composed of the same number of the same atoms do exist the only difference in whose properties is a purely physical one, we may still, I think, be able to explain the existence of such truly "physically isomeric" bodies, either upon the supposition that the affinities of many atoms differ in value, or by supposing that these affinities are originally of equal value, but that the "saturation" of some of them modifies those which remain.

10. It has been supposed that those elements which are capable of assuming allotropic forms may sometimes exist in these forms in their compounds $\uparrow$. The existence of allotropic forms of elementary substances is closely allied with the existence of isomeric forms of compound substances. The same or very similar explanations are probably applicable in both cases; in the case of elements we shall have to deal with atomic interchanges of similar atoms only. If we grant variability of affinities, we may suppose that the nature of the particular allotrope produced by the mutual action of two ele-

* Phil. Mag. [IV.] vol. xxviii. p. 364.

$\dagger$ See Weber in this Magazine [IV.] vol. xlix. p. 300 ; also Wiedemann, Pogg. Ann. vol. clvii. p. 41, a translation of which appears in the August Number of the Philosophical Magazine. 
mentary atoms will be influenced by the position of the affinities mutually satisfied; or if we prefer to regard the elementary atomic affinities as of equal value, we may still suppose that the mutual action of two elementary atoms will so modify the residuary affinities as to render possible the formation of allotropic forms according to the position in the molecule occupied by a third atom, which now comes within the sphere of action of the molecule. Or it may very possibly be that both of these causes influence the formation of allotropes. We certainly know that the density of some allotropic forms of the same element is not a constant number; it appears also that changes of energy accompany the changes of an elementary molecule from one allotropic form to another.

11. Isomerism does not appear to occur among inorganic compounds to so marked an extent as among the compounds of carbon. A variety of silver chloride has been described by Field ${ }^{*}$, which is unacted upon by light, and is distinctly crystalline; so, also, we know of two modifications of nitrogen tetroxide, $\mathrm{N}_{2} \mathrm{O}_{4}$ and $\mathrm{NO}_{2}$. A systematic search for isomeric bodies among the non-carbon compounds would doubtless meet with a considerable degree of success.

XXIII. Supplementary Discussion of the Hydrodynamical Theory of Attractive and Repulsive Forces. By Professor Challis, M.A., F.R.S., F.R.A.S.†

1. TN the mathematical theories of the physical forces which 1 from time to time I have proposed and discussed in this Journal, the reasoning has been uniformly made to rest on the following principles :-

All visible and tangible substances consist of atoms.

An atom is a very small inert spherical mass of constant form and magnitude.

All space not occupied by atoms is filled by a perfectly fluid substance (the æther), of uniform pressure and density when at rest, and varying in pressure when in motion in exact proportion to variations of its density.

All physical force acts either as pressure of the xther upon the surfaces of atoms, or as reaction of the atoms upon the ather by reason of the constancy of their form and magnitude.

2. The selection of these hypotheses has been determined

* Chem. Soc. Journ. vol, x. p. 242.

t Communicated by the Author. 